\title{
Contribution of Dobutamine Stress Echocardiography in the Management of Advanced Ischemic and Valvular Heart Diseases in Senegal
}

El Hadji Mbacke Sarr ${ }^{1}$, Ousmane Dieye ${ }^{1}$, Adama Sawadogo ${ }^{2 *}$, Mohamed Leye ${ }^{3}$, Momar Dioum $^{1}$, Kadia Ba $^{1}$, Dominique Bindia $^{1}$, Arame Diagne Diallo ${ }^{1}$, Magalie Kaya ${ }^{1}$, Simon Manga ${ }^{1}$ and Ibrahima Bara Diop ${ }^{1}$

${ }^{1}$ Department of Cardiology, Cheikh Anta Diop University of Dakar, Senegal, West Africa

${ }^{2}$ Department of Cardiovascular and Thoracic Surgery, Cheikh Anta Diop University, Senegal, West Africa

${ }^{3}$ Unit of Training and Research in Medical Sciences, University of Thies, Senegal, West Africa

Received: 29 July, 2017; Accepted: 04 September, 2017; Published: 11 September, 2017

*Corresponding author: Adama Sawadogo, Department of Cardiovascular and Thoracic Surgery, Cheikh Anta Diop University, Senegal, West Africa, Email: adamsaw2000@yahoo.fr

\begin{abstract}
Background: Stress echocardiography is the combination of 2D echocardiography with a physical, pharmacological, or electrical stress. It is a cornerstone in the evaluation of patients with coronary artery disease. In contrast, valvular heart disease is usually considered static and its management relies upon resting evaluation only.

Methods: It consisted of transversal and descriptive study of the indications and outcomes of Dobutamine Stress Echocardiography (DSE) that have been performed at the University Hospital of Fann in Dakar, Senegal, between November 2015 and December 2016.

Results: 152 patients were enrolled in the study. There were $54.60 \%$ of females; the mean age was $61.07( \pm 10.19)$ years old ranging from 20 to 80 years old. The indications for DSE included myocardial Contractile Reserve (CR) in $85 \%$, myocardial viability in $8 \%$ and myocardial ischemia in $7 \%$. The 2D radial strain echocardiography was normal in $82.9 \%$ and decreased in $17.1 \%$. The CR assessment (11 patients) was positive in $45.45 \%$ and negative in $54.55 \%$. The myocardial viability (12 patients): it was positive in $33.34 \%$ and negative in $66.66 \%$. The myocardial ischemia: it was positive in $20.93 \%$ and negative in $79.06 \% .32 .9 \%$ presented minor side effects.

Conclusion: It is possible to perform DSE in a setting of low income country such us Senegal. This exam is affordable and useful for better management of ischemic and valvular heart diseases in our context. Another study in our region that involves more patients may consolidate these findings.
\end{abstract}

Keywords: Dobutamine Stress Echocardiogram; Strain echocardiography; Ischemic Heart; Heart Valve disease; Senegal

\section{Introduction}

In Senegal, rheumatic heart disease prevalence rates were 1.5 cases per 1000 using clinical criteria and 7.5 cases per 1000 if echocardiographic screening was used according to Kane [1]. Stress testing is a cornerstone in the evaluation of patients with coronary artery disease and its results are always integrated into any clinical decisions. In contrast, valvular heart disease is usually considered static and its management relies upon resting evaluation only [2]. Stress echocardiography is the combination of 2D echocardiography with a physical, pharmacological, or electrical stress [3]. In this study, the authors report the inaugural experience of their department in the contribution of the dobutamine stress echocardiography in the management of the ischemic and valvular heart diseases.

\section{Methods}

\section{Type of Study}

This study shows the indications and outcomes of Dobutamine Stress Echocardiography (DSE) that have been performed at the University Hospital of Fann, Dakar, Senegal, between November 2015 and December 2016. It consisted of transversal study that used descriptive method based on the database from the department of cardiology.

\section{Population of Study}

Included were all patients who underwent DSE for anginalike chest pain with no modified electrocardiogram, valvular diseases with low LVEF and severely diseased coronary arteries on coronary angiography prior to Percutaneous Coronary 
Intervention (PCI). In valvular heart diseases, DSE was indicated in severely decreased LVEF to prevent post-CBP alteration. Indications for strain in DSE were to describe the different grades of myocardial wall segments' modifications and the severity of myocardial viability. Those who presented unstable hemodynamics were excluded.

\section{The Testing Procedure}

The patients fasted for 4 hours prior to the test. Two procedures based on the dose of dobutamine were used: First, a low-dose dobutamine $(5-20 \mu \mathrm{g} / \mathrm{kg} / \mathrm{min})$ to assess myocardium viability and Contractile Reserve (CR); an increase of at least $20 \%$ during the stress meant there was existing contractile reserve. Second, a high-dose dobutamine $(40 \mu \mathrm{g} / \mathrm{kg} / \mathrm{min})$ for assessment of myocardial ischemia. Echocardiograms were performed by a trained cardiologist who was assisted by a second cardiologist, an intensivist and a registered nurse. The longitudinal 2D strain echocardiography was assessed respectively in 2, 3 and 4-cavity views. The assessment was based on a change in the Wall Motion Score Index $(\triangle \mathrm{WMSI})$ and $\triangle \mathrm{LVEF}$ during DSE. Positive response was defined as an increase in LVEF to $>50 \%$ testing. The sensibility of our laboratory was $91 \%$ and the specificity, $87 \%$. In the patients who presented a slow action of dobutamine, atropine was used to stimulate the vagal nerve. We managed the side effects of dobutamine by either a rapid recovery protocol using Brevibloc $^{\circledR}$ (esmolol) or by a slow recovery with Propranolol.

\section{Data Collection and Analysis}

We took the number of patients on whom the DSE was performed and broke down the statistics to show parameters that included age, sex, indication, result and complication of the investigation. IBM $^{\circledR}$ SPSS $^{\circledR}$ Statistics Version 22 was used to analyze statistics.

\section{Results}

\section{Sex}

Overall, 152 patients were enrolled in the study. This population was dominated by the females, 83 (54.60\%); the males (69) represented $45.40 \%$

\section{Age}

The mean age was 61.07 ( $S D \pm 10.19$ ) years old ranging from 20 to 80 years old. However, more than half the population was in their $60 \mathrm{~s}(59.45 \%)$. The two other well represented class of ages were those on their 50s (22.6\%) and 70s (13.81\%). The range of ages from 50 s to 70 s represented $95.86 \%$ (Figure1).

\section{Indications for Stress Echography}

Regarding the nosology, the clinical features in which DSE was indicated have been classified into three groups. They included assessment of myocardial Contractile Reserve (CR) in 129 patients $(85 \%)$, myocardial viability in $12(8 \%)$ and myocardial ischemia in 11 (7\%) (Table1).

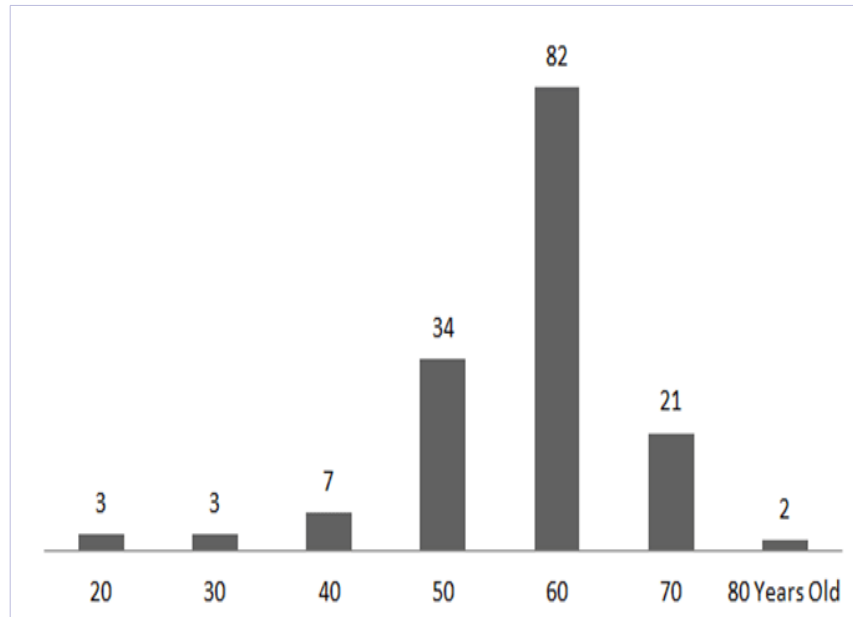

Figure 1: Age distribution of patients $(n=152)$

\begin{tabular}{|c|c|c|}
\hline \multicolumn{2}{|l|}{ Table 1: Indications for DSE } \\
\hline Indication & Number & Percentage \\
\hline Contractile reserve & 11 & 7 \\
\hline Myocardial viability & 12 & 8 \\
\hline Myocardial ischemia & 129 & 85 \\
\hline Total & $\mathbf{1 5 2}$ & $\mathbf{1 0 0}$ \\
\hline
\end{tabular}

\section{D Strain Echocardiography (Figure 2 and 3)}

Of the 152 patients, the longitudinal strain echocardiography was normal in 126 patients (82.9\%) and decreased in $26(17.1 \%)$. The 26 decreased cases included 23 ischemic heart diseases, 2 Hypertrophic Cardiomyopathy and 1 aortic stenosis.

\section{Response to the Stress}

The CR assessment (11 patients): it was positive in 5 patients (45.45\%) and negative in 6 (54.55\%). Regarding the myocardial viability (12 patients): there were 4 positive cases (33.34\%) and 5 negative $(66.66 \%)$. Amongst the 129 cases of myocardial ischemia assessment, 27 (20.93\%) were positive versus 102 (79.06\%) negative (Figure 4).

\section{Side effects of Dobutamine}

Some side effects (Table 2) were noticed in 50 patients $(32.9 \%)$ over the procedure. These cases included vagal choc in 7 patients (4.60\%), precordial pain in $24(15.8 \%)$ and digestive troubles such as nausea and vomiting in 19 (12.5\%).

\section{Decision Made Following the Testing}

DSE helped to make therapeutic decision as followings: 76 patients $(50 \%)$ benefited from medical treatment; $11(7.24 \%)$ underwent PCI and 4 (2.63\%) underwent CABG. 


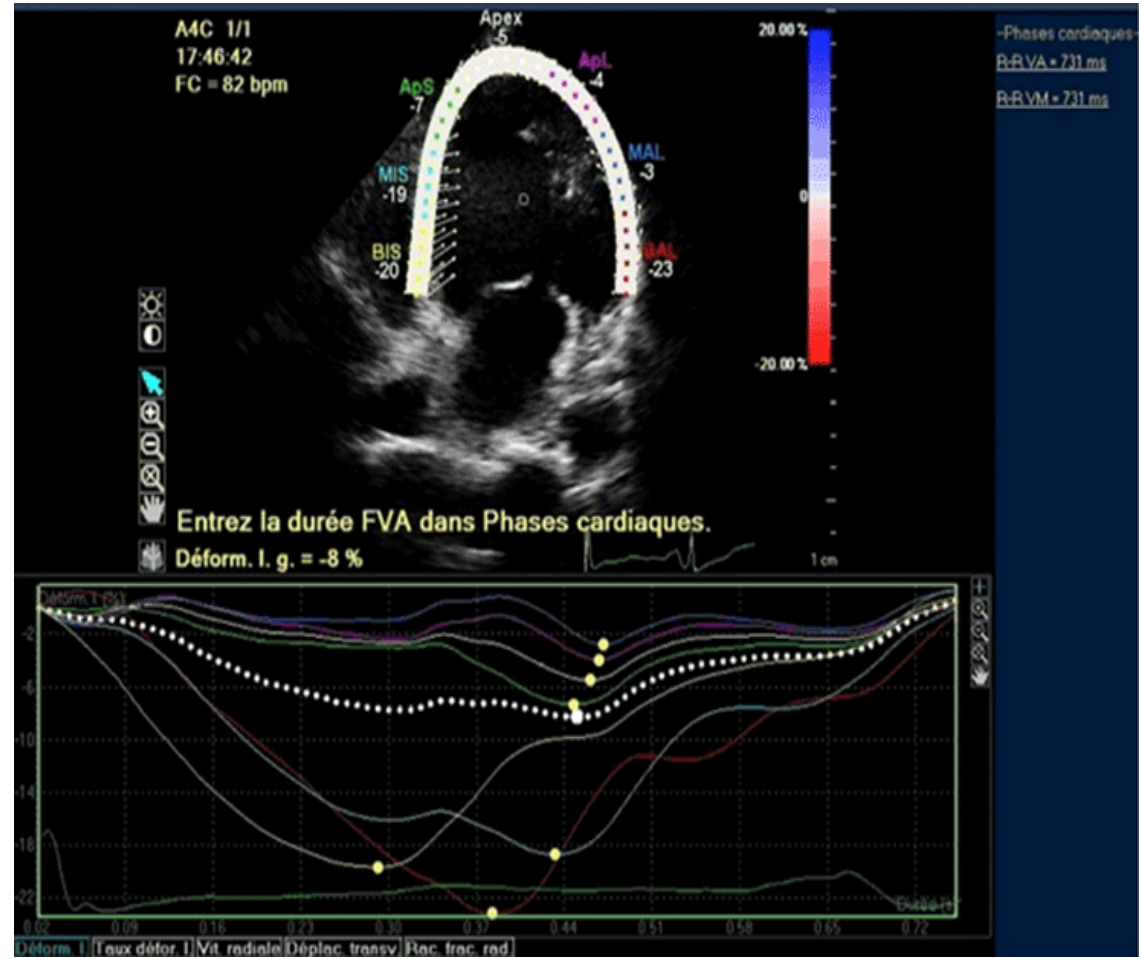

Figure 2: Longitudinal strain echocardiogram view in a patient

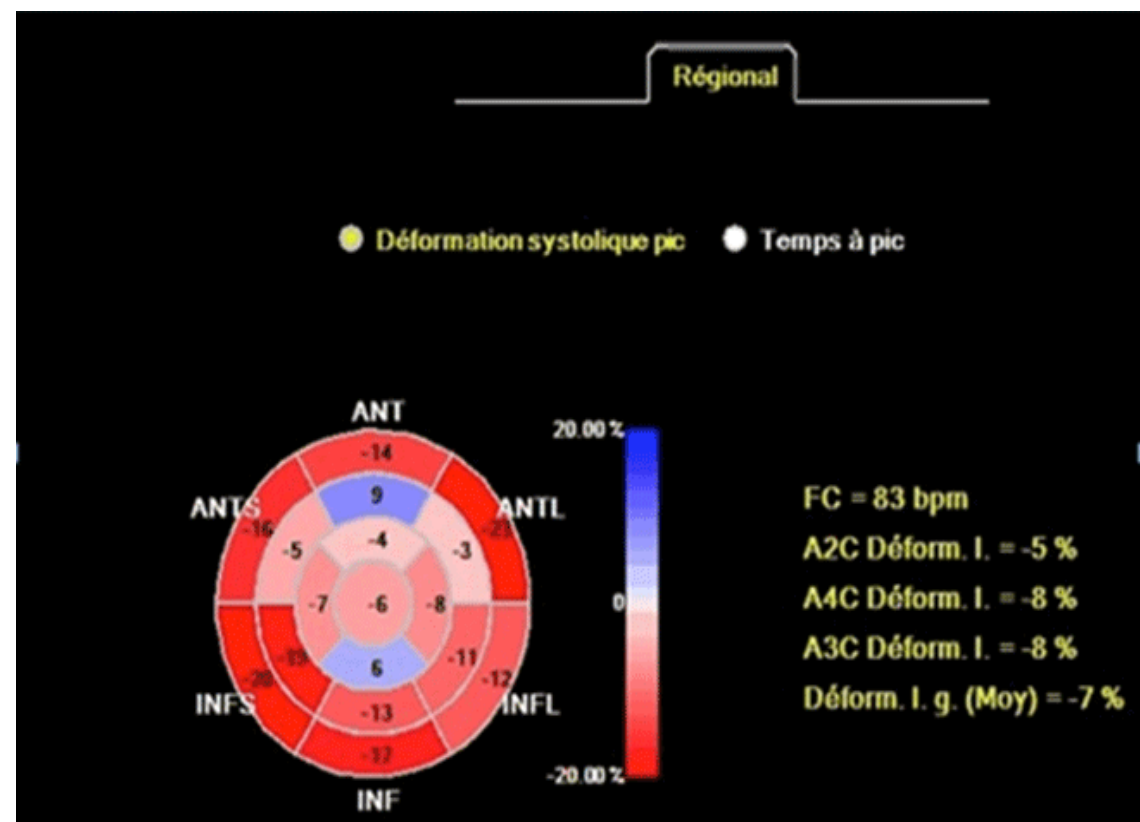

Déformation systolique pic

Figure 3: Bull's eye map of left ventricular strain

Citation: Sarr EM, Dieye O, Adama S, et al. (2017) Contribution of Dobutamine Stress Echocardiography in the Management of Advanced Ischemic and Valvular Heart Diseases in Senegal. J Cardiovascular Thoracic Surgery 2(4): 1-5. DOI: 10.15226/2573- 


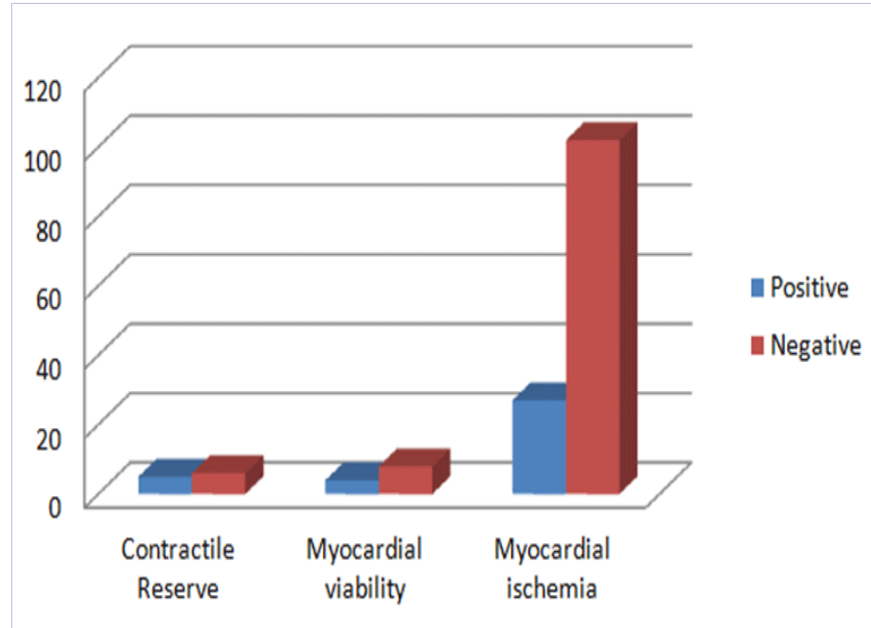

Figure 4: Outcomes of DSE $(n=152)$

\begin{tabular}{|c|c|c|c|}
\multicolumn{2}{|c|}{ Table 2: Events over DSE } \\
Event & & Number & Percentage \\
\hline Uneventful & & 102 & 67.10 \\
\hline \multirow{2}{*}{ Side effect } & Vagal choc & 7 & 4.60 \\
\cline { 2 - 4 } & Precordial pain & 24 & 15.80 \\
\cline { 2 - 4 } & $\begin{array}{c}\text { Digestive } \\
\text { trouble }\end{array}$ & 19 & 12.50 \\
\hline \multirow{2}{*}{ Total } & & $\mathbf{1 5 2}$ & $\mathbf{1 0 0 . 0 0}$ \\
\hline
\end{tabular}

\section{Discussion}

This study relating to the DSE is probably the first series within French West Africa and it intends to highlight the basic data of this procedure. The females dominated the population of study. One reason is that this gender is more likely to suffer from rheumatic heart disease in the developing countries [4]. However, gender-related differences in the prevalence of ischemic heart disease have not been clearly shown in sub-Saharan Africa [5]. Moreover, the International Atherosclerosis Project found very little gender-related difference in advanced coronary lesions in a study on black South Africans [6]. The vast majority of our patients (95.86\%) were aged between 40 and 70 years old. In fact, the occurrence of coronary artery disease increases from the age of 40 years old [7]. The most common indication for stress echocardiography is evaluation of myocardial ischemia [8]. The basic principle is identification and localization of areas of ischemia by detecting new or worsening wall motion abnormalities. For patients without a prior diagnosis of CAD, stress echocardiography can be used to detect inducible ischemia. Like in 12 patients of our series, another clinical useful application of DSE is to determine myocardial viability. Thus "Hibernating" myocardium refers to viable but under-perfused myocardial tissue that regains functionality after revascularization [9]. DSE has the ability to assess valvular function, both at rest and during stress; stenosis and regurgitation of all valves can be evaluated with stress echocardiography, although the most common stress echocardiogram applications are in left-sided stenotic lesions [2]. Echocardiographic strain and strain-rate imaging (deformation imaging) is a new non-invasive method for assessment of myocardial function Tissue Doppler imaging (TDI), also known as Tissue Velocity Imaging (TVI), is currently accepted as a sensitive and sufficiently accurate echocardiographic tool for quantitative assessment of cardiac function $[10,11]$. Overall, the testing showed better defined images; moreover, it described the cardiac lesions with more precision making possible to plan the management and to discuss the prognosis. In the literature, the importance of DSE is undoubtable. Stress echocardiography has the highest specificity (88\%) among the ischemic tests including traditional exercise ECG testing, thallium perfusion imaging, Single Photon Emission Computed Tomography (SPECT), and Positron Emission Tomography (PET) [12]. Accounting for differences in costs, stress echocardiography seems to be more efficient than SPECT [13]. Therefore, in the Sub-Saharan Africa that is characterized by a low-income setting, this complementary investigation is to be spread. The benefits of DSE outweigh its disadvantages as we did not notice a major complication. Safety profile of stress echocardiography depends on the stressor used. Exercise is the safest stressor as shown in large samples with the long - lasting experience of ECG stress test [14]. Stress echo registries collecting data on thousands of patients have shown that exercise is the safest test [15-18]. Death has an incidence rate of 1 in 10,000 tests. Major life-threatening effects (myocardial infarction, ventricular fibrillation, sustained ventricular tachycardia, and stroke) occur in about 1 in 6000 patients with exercise in the international stress echocardiography registryfivefold less than with dipyridamole echocardiography and tenfold less than with dobutamine echocardiography.

\section{Conclusion}

It is possible to perform DSE in a setting of low income country such us Senegal. This exam is affordable and useful for better management of ischemic and valvular heart diseases in our context. Another study in our region that involves more patients is to be carried out in order to consolidate these findings.

\section{References}

1. Kane A. Prevalence of rheumatic heart disease in Senegal, an echocardiographic screening. Arch Cardiovascular Dis Supplements. 2011;3(1):43.

2. Piérard L, Lancellotti P. Stress testing in valve disease. Heart. 2007;93(6):766-772. doi: 10.1136/hrt.2005.074815

3. Picano E. Stress echocardiography. 6th ed. Heidelberg: Springer Verlag; 2015.

4. Sani MU, Karaye KM, Borodo MM. Prevalence and pattern of rheumatic heart disease in the Nigerian savannah: an echocardiographic study. Cardiovasc J Afr. 2007;18(5):295-299.

5. Akinboboye 0, Idris 0, Akinboboye 0, 0 Akinkugbe. Trends in coronary artery disease and associated risk factors in sub-Saharan Africans. J Hum Hypertension. 2003;17(6):381-387. doi: 10.1038/ sj.jhh.1001562 
6. Ticolat P, et al. Epidemiological data concerning coronary disease in black Africans (103 cases). Results of the CORONAFRIC Multicenter Study. Trop Cardiol. 1991;17:20.

7. Mozaffarian D et al. Circulation. 2015;131:29-322.

8. Gilstrap LG, Bhatia RS, Weiner RB, Dudzinski DM. Dobutamine stress echocardiography: a review and update. Res Reports Clin Cardiol. 2014;5:69-81.

9. Alderman EL, Fisher LD, Litwin P, Kaiser GC, Myers WO, Maynard C, et al. Results of coronary artery surgery in patients with poor left ventricular function (CASS). Circulation. 1983;68(4):785-795.

10. Mathias W Jr, Tsutsui JM, Andrade JL, Kowatsch I, Lemos PA, Leal SM, et al. Value of rapid beta-blocker injection at peak dobutamine-atropine stress echocardiography for detection of coronary artery disease. J Am Coll Cardiol. 2003;41(9):1583-1589.

11. Hays JT, Mahmarian JJ, Cochran AJ, Verani MS. Dobutamine thallium-201 tomography for evaluating patients with suspected coronary artery disease unable to undergo exercise or vasodilator pharmacologic stress testing. J Am Coll Cardiol. 1993;21(7):15831590.

12. Garber AM, Solomon NA. Cost-effectiveness of alternative test strategies for the diagnosis of coronary artery disease. Ann Intern Med. 1999;130:719-728.
13. Fleischmann KE, Hunink MG, Kuntz KM, Douglas PS. Exercise echocardiography or exercise spect imaging? A meta-analysis of diagnostic test performance. J Am Med Assoc. 1998;280(10):913-920.

14. Fletcher GF, Balady GJ, Amsterdam EA, Chaitman B, Eckel R, Fleg J, et al. Exercise standards for testing and training: a statement for healthcare professionals from the American Heart Association. Circulation. 2001;104(14):1694-1740.

15. Varga A, Garcia MA, Picano E, International Stress Echo Complication Registry. Safety of stress echocardiography (from the International Stress Echo Complication Registry). Am J Cardiol. 2006;98(4):541543.

16. Picano E, Marini C, Pirelli S, Maffei S, Bolognese L, Chiriatti G, et al. Safety of intravenous high-dose dipyridamole echocardiography. The Echo-Persantine International Cooperative Study Group. Am J Cardiol. 1992;70(2):252-258.

17. Picano E, Mathias W Jr, Pingitore A, Bigi R, Previtali M. Safety and tolerability of dobutamine-atropine stress echocardiography: a prospective, multicenter study. Echo Dobutamine International Cooperative Study Group. Lancet. 1994;344:1190-1192.

18. Beckmann S, Haug G. National registry 1995-1998 on 150,000 stress echo examinations side effects and complications in 60,448 examinations of the registry 1997-1998. Circulation. 1999;100(Suppl):3401A. 